\title{
Terminologia: conceitos e aplicações
}

\section{Cláudia Augusto Dias}

Mestranda em ciência da informação na Universidade de Brasília (UnB). Formada em engenharia elétrica pela Universidade de Brasília. Trabalha como auditora de sistemas no Tribunal de Contas da União (TCU).

E-mail:claudiaad@yahoo.com

\section{Resumo}

Análise da perspectiva poliédrica da terminologia como um objeto, uma prática ou uma disciplina, comparando diferentes pontos de vista. O propósito desta análise é destacar a natureza interdisciplinar da terminologia e suas aplicações práticas na moderna era da informação.

\section{Palavra-chave}

Terminologia.

\section{INTRODUÇÃO}

Apesar de ter sido definida pela International Organization for Standardization (ISO) apud Sonneveld ${ }^{3}$ como qualquer atividade relacionada com a sistematização e representação de conceitos ou apresentação de termos baseados em princípios e métodos estabelecidos e ainda como um conjunto de termos que constituem um sistema de conceitos de uma determinada área, não há um consenso ou uma definição hermética do que vem a ser a terminologia.

Cabré aponta, como motivos para essa diversidade de definições, a perspectiva "poliédrica" da terminologia com relação a seus fundamentos, seus enfoques e suas aplicações práticas, além da conhecida polissemia do termo terminologia, que tanto pode ser usado para designar uma disciplina, uma prática ou o produto gerado por essa prática ${ }^{1}$.

Sager concorda com Cabré e afirma que, como teoria, a terminologia é um conjunto de premissas, argumentos e conclusões necessário para explicar o relacionamento entre conceitos e termos especializados; como prática, é um conjunto de métodos e atividades voltado para coleta, descrição, processamento e apresentação de termos; como produto, é um conjunto de termos, ou vocabulário, de uma determinada especialidade ${ }^{2}$.

\section{A TERMINOLOGIA COMO OBJETO}

Até mesmo quando tratada sob apenas uma dessas perspectivas, a terminologia apresenta significados diversos. Se tomada como objeto, isto é, a terminologia como um conjunto de termos de uma especialidade, notase que cada área do conhecimento aborda seus termos de forma diferente. Cabré ressalta três diferentes concepções sobre os termos. Para a lingüística, os termos são o conjunto de signos lingüísticos que constituem um subconjunto dentro do componente léxico da gramática de determinada pessoa. Os termos, para a lingüística, são uma forma de saber. Para a filosofia, a terminologia é um conjunto de unidades cognitivas que representam o conhecimento especializado. É, portanto, uma forma de conhecer. E, por fim, para as diferentes disciplinas técnico-científicas, a terminologia é o conjunto das 
unidades de expressão e comunicação que permitem transferir o pensamento especializado. Portanto, é uma forma de transferir, de comunicar ${ }^{1}$.

\section{A TERMINOLOGIA COMO DISCIPLINA}

Na concepção da terminologia como disciplina, também existem correntes divergentes na literatura. Alguns autores, adeptos da teoria geral da terminologia, defendem que essa matéria é autônoma e auto-suficiente, considerando-a uma disciplina original, dotada de fundamentos próprios, apesar de conectada historicamente a outras disciplinas. Outros autores consideram-na como parte de outra disciplina, como, por exemplo, a lingüística e a filosofia, constituindo-se em um apêndice, sem qualquer autonomia. Há também outros autores que defendem sua autonomia, mas destacam seu caráter interdisciplinar, ao agregar conceitos e métodos de outras disciplinas e ser influenciada pelas áreas técnicocientíficas às quais presta serviços.

Dentre os autores defensores dessa terceira vertente, destacam-se Sonneveld e Cabré. Segundo Sonneveld, a disciplina terminologia congrega conhecimentos oriundos de diferentes ciências, como a informática (engenharia do conhecimento e inteligência artificial), a lingüística (semântica, lexicologia e tradução), as ciências da documentação e classificação, a conceptologia e a nomenclatura. Essa síntese, no ponto de vista de Sonneveld, resultou em um campo de estudo multidisciplinar com métodos e princípios próprios ${ }^{3}$.

Cabré reforça a idéia da terminologia como uma interdisciplina, constituída por elementos procedentes de outras disciplinas, porém com bases teóricas delimitadas e objeto de estudo definido ${ }^{1}$. Cabré não considera a terminologia uma disciplina original em seu sentido mais amplo, mas sim em sentido restrito, pois, em sua concepção, é uma disciplina que, ao tomar alguns fundamentos de outras disciplinas, seleciona elementos de cada uma delas e constrói um espaço próprio e original, diferenciado dos outros campos científicos ${ }^{1}$.

\section{A TERMINOLOGIA COMO PRÁTICA}

Contrapondo-se a essa visão de Cabré e Sonneveld, Sager nega o status independente da terminologia como uma disciplina, preferindo defini-la como um conjunto de práticas que evoluiu no contexto da criação de termos, sua coleta, explicação e apresentação em diferentes meios impressos e eletrônicos ${ }^{2}$. Apesar de serem práticas bem estabelecidas, segundo Sager, não configuram uma disciplina, pois as disciplinas estabelecem conhecimentos sobre as coisas, enquanto as metodologias são apenas meios para atingir um objetivo final, como é o caso da terminologia ${ }^{2}$.

Como uma tentativa de conciliar todas essas vertentes, a Associação Internacional de Terminologia apud Sager ${ }^{2}$ definiu-a como "estudo e uso de sistemas de símbolos e signos lingüísticos empregados na comunicação humana em áreas especializadas do conhecimento". Essa definição ainda aborda o aspecto interdisciplinar da terminologia e ressalta que, como disciplina aplicada, a terminologia se relaciona com a lexicografia e usa técnicas da ciência e da tecnologia da informação.

\section{APLICAÇÕES DA TERMINOLOGIA}

Fundamentalmente, a terminologia se aplica à comunicação direta, à mediação comunicativa e ao planejamento lingüístico. Na área de documentação, a terminologia é essencial para representar o conteúdo dos documentos e para facilitar o acesso a esse conteúdo. Cabré cita os tesauros e as classificações como inventários terminológicos organizados de acordo com sua temática e controlados formalmente ${ }^{1}$.

Para a engenharia lingüística, a terminologia é a área que simula o conhecimento, utilizando-se da própria engenharia lingüística para organizar e facilitar seu processo de trabalho, armazenar a informação terminológica e construir um posto de trabalho terminográfico adequado aos avanços das tecnologias da informação e comunicação.

Em um contexto mais genérico, a terminologia representa o conhecimento técnico-científico especializado de forma organizada, por meio de manuais e glossários, e unifica esse conhecimento sob a forma de normas e padrões. Sem a terminologia, os especialistas não conseguiriam se comunicar, repassar seus conhecimentos, nem tampouco representar esse conhecimento de forma organizada. Nesse sentido, Cabré atribui à terminologia a qualidade de ser a base do pensamento especializado ${ }^{1}$.

\section{A TERMINOLOGIA E A ORGANIZAÇÃO DA INFORMAÇÃO}

Mais recentemente a terminologia tem servido a aplicações mais práticas e próximas da realidade cotidiana da sociedade. Com a atual explosão da informação, a 
diversidade de termos técnicos e científicos advindos das novas tecnologias, a necessidade de comunicação internacional mais eficiente e a crescente demanda por maior rapidez e facilidade na recuperação de informações dispersas em inúmeros bancos de dados, arquivos e outros meios eletrônicos, faz-se necessário o desenvolvimento de sistemas mais avançados e efetivos de organização e gestão de informações, baseados em uma metodologia de processamento de dados terminológicos.

Sonneveld ressalta que, para ser capaz de sistematizar as informações de uma base de dados, ou para analisar imensos volumes de dados recuperados de sistemas distintos, o vocabulário da área em questão deve ser muito bem controlado ${ }^{3}$. Para que esses vocabulários e os chamados bancos de dados terminológicos funcionem de forma eficiente, pode-se contar com o auxílio dos princípios e métodos da terminologia e da terminografia computadorizada.

\section{CONCLUSÃO}

Em síntese, a coleta, a descrição, o processamento e a apresentação de informações a respeito de termos padronizados para a compilação de glossários, dicionários e bancos de dados terminológicos representam uma nova perspectiva para a terminologia, como metodologia ou área de estudo multidisciplinar, associada à prestação de serviços de informação para a sociedade.

\section{REFERÊNCIAS BIBLIOGRÁFICAS}

1. CABRÉ, Maria Teresa. La terminología hoy: concepciones, tendencias y aplicaciones. Ciência da Informação. v. 24, n. 3, 1995.

2. SAGER, Juan Carlos. A practical course in terminology processing. Amsterdam, Philadelphia: J. Benjamins, 1998.

3. SONNEVELD, H. B. et al. Terminology : applications in interdisciplinary communication. Amsterdam, Philadelphia: J. Benjamins, 1993. 